\section{Revelando un archivo inactivo que contiene nueve proyectos académicos de diseño industrial de 1981}

\section{Revealing an inactive file that contains nine academic industrial design projects 1981}

\author{
Camilo Andrés Angulo Valenzuela
}

(E) PhD. en Diseño y Creación de la Universidad de Caldas V Cohorte

\begin{abstract}
Resumen
Cuando se realiza un ejercicio de reconstrucción histórica se busca acceder, por un lado, a la información primaria desde los protagonistas y sus pensamientos, y por otro, a evidencias secundarias proporcionadas por objetos, imágenes o escritos. En el caso particular del presente escrito, el interés se centró en conseguir registros visuales, esencialmente fotografías o diapositivas, que evidenciaran proyectos académicos realizados por aquellos primeros estudiantes de diseño industrial en Colombia. Lo anterior permite, en alguna medida, contrastar la visión que tenía la academia con la propuesta del gobierno respecto a las políticas públicas de la industria para la época. Fue durante esta indagación que de manera sorprendente, se encontró en la bodega del programa de diseño industrial de la Universidad Jorge Tadeo Lozano, un archivo muerto del año 1981 con nueve (9) fotografías impresas que relacionaban proyectos académicos, los cuales fueron insumo para la presente reflexión..
\end{abstract}

Palabras clave: Diseño industrial, proyecto, representación visual, fotografía, política pública..

\begin{abstract}
This article summarizes a research conducted with seventh grade students of the E.I. CASD in the city of Armenia (Q), about the learning of the additive and multiplicative system of the integer numbers through Virtual Learning Objects (VLO). Also it shows the transformation of the learning units to the learning objects, which serves as a motivator axis for the development of classes. Recognizing that mathematics education is constantly changing, the starting point is a set of methodological strategies to address the object of study, until reaching the learning of the object of study through a technological mediation, which became a strategy that allows us to reduce learning difficulties. In this sense, an adaptation, innovation and implementation of information technology and communication in the learning objects, students are expected to acquire the math skills established by the Ministry of National Education (MEN); from concept additive and multiplicative system in the theoretical framework of Vergnaud conceptual fields. From the information obtained, are designed OVA additive and multiplicative systems of integers so as to be easily accessible, interoperable and reusable.
\end{abstract}

Keywords: Industrial Design, projects, visual representation, photography, public policy
Recibido: $18 / 02 / 2015$

Revisado: 05/07/2015

Aceptado: 10/12/2015

Correspondencia de autor:

camilo.angulo@utadeo.edu.co

(C) 2015 Universidad La Gran Colombia. Este es un artículo de acceso abierto, distribuido bajo los términos de la licencia Creative Commons Attribution License, que permite el uso ilimitado, distribución y reproducción en cualquier medio, siempre que el autor original y la fuente se acrediten.

\section{Cómo citar:}

Angulo C.A.

Revelando un archivo inctivo que contiene nueve proyectos académicos de Diseño Industrial. UGCiencia 21, 103-113. 


\section{Introducción}

Un grupo de profesores de planta del programa de diseño industrial de la Facultad de Artes y Diseño de la Universidad Jorge Tadeo Lozano de Bogotá se han interesado por reconstruir parte de la historia académica del diseño en Colombia, desde las vivencias y materializaciones de la institución en que laboran. Entre algunos de los profesores pertenecientes a esta última década que han contribuido con esta tarea, se encuentran Alfredo Gutiérrez, Camilo Angulo y Lorena Guerrero.

El profesor Gutiérrez con la colaboración del profesor Angulo, escribieron un documento titulado Cuatro décadas del diseño industrial tadeista, que se encuentra en proceso de ser publicado y cuyos capítulos hablan sobre la figura histórica de Jorge Tadeo Lozano y su relación con el diseño, los preámbulos en el año de 1973, el primer quinquenio comprendido entre los años 1974 a 1978 (el nacimiento), el segundo quinquenio entre 1979-1983 (el reconocimiento), el tercer quinquenio de 1984-1988 (el pensamiento sistémico), el cuarto quinquenio 1989-1993 (el agro y la salud), el quinto quinquenio de 1994-1998 (exploración y expansión), el sexto quinquenio de 1999-2003 (de los objetos a las ciudades), el séptimo quinquenio de 2004-2008 (la multiplicidad de enfoques) y el octavo quinquenio de 2009-2014 (las trayectorias de la artificialidad).

En lo que respecta a la historia reciente, el profesor Angulo realizó, por un lado, un registro fotográfico de las actividades de programa tadeísta que acontecieron entre los años 2008 y 2012, el cual fue publicado en el segundo número de la revista de divulgación del programa de diseño industrial tadeísta llamada Imaginarios. Y por otro, un texto corto que pretendió rastrear las raíces documentadas sobre el origen de las escuelas de diseño en Colombia, tanto desde la historia del diseño de la profesora Silvia Fernández (2009), como la visión de la profesionalización del diseño del profesor Juan Buitrago (2011), publicado en el portal Foroalfa de Argentina, bajo el título The Roots of Industrial Design Colleges in Colombia. Por su lado la profesora Guerrero, escribió un texto titulado El diseño industrial tadeista frente a las políticas públicas de la industria: 1979-2013 que hasta el momento se encuentra sin publicar.

Fue en el trascurrir del año 2014 que los anteriores ingredientes fueron condensados en un proyecto de investigación financiado por La Tadeo y liderado por el profesor Alfredo Gutiérrez, el cual pretendía dar una mirada retrospectiva sobre los últimos 40 años desde los protagonistas de la historia del diseño tadeísta, sus pensamientos y materializaciones, con la intensión de lanzar una perspectiva para los próximos 40 años. Pero que a la postre, se convirtió en un pretexto para conocer un panorama amplio de experiencias de vida, de sus egresados, estudiantes, docentes y administrativos.

Y fue durante el trabajo de campo de este proyecto de investigación, más exactamente cuando se realizaba la etapa de búsqueda de documentos e imágenes, que en la bodega donde se guardan los archivos inactivos del Programa de Diseño Industrial tadeísta en la ciudad de Bogotá, la profesora Guerrero descubrió un valioso documento correspondiente al año de 1981, empastado en color verde oscuro, con 153 hojas envejecidas por el tiempo, bajo el título de Informe presentado por la Facultad de Diseño Industrial con destino al Instituto Colombiano para el Fomento de la Educación Superior, donde se encontró una nutrida información sobre la primera etapa de evolución de la aquella entonces denominada Facultad de Diseño Industrial. En ese documento, al interior de la página titulada tabla de contenido, se relacionaban temas como generalidades del programa, administración del programa, plan de estudios, personal docente, recursos disponibles, estudiantes, planes de desarrollo y proyectos de alumnos; este último capítulo acompañado por nueve fotografías blanco y negro con una dimensión aproximada de $10,5 \times 10,5$ centímetros, donde se retrataron igual número de proyectos de los estudiantes. El estudio fotográfico estuvo acompañado por una breve descripción
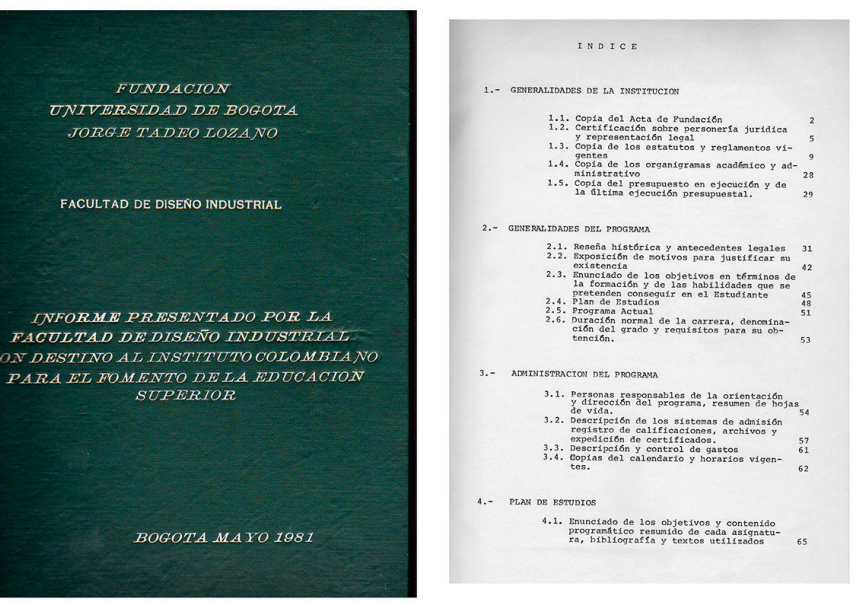
que permitía inferir la intención que tuvo cada autor sobre el diseño de su proyecto.

\section{Contexto histórico-académico}

Al final de la década de los años cincuenta, el arquitecto Álvaro Ortega al regresar de cursar estudios en el exterior, realizó en la Universidad de Los Andes la primera propuesta de una asignatura que implementó temas de Diseño Básico, toda una novedad para el momento. A partir de ese evento académico, una generación de arquitectos disidentes de su profesión como fueron: Hernando Vargas, Rogelio Salmona, Dicken Castro, Arturo Robledo, entre otros, tuvieron directa o indirectamente relación con la Universidad Nacional de Colombia, y señalaron el camino para la fundación de programas de diseño industrial en nuestro país. De esta manera, en 1973, la Universidad Pontificia Bolivariana de Medellín funda un programa de diseño genérico y en el mismo año, la Universidad Jorge Tadeo Lozano funda el primer programa de posgrado en Diseño Industrial.
En lo que respecta a la historia de La Tadeo, fue fundada el 5 de febrero de 1954 a manos del geógrafo peruano Javier Pulgar Vidal, el abogado colombiano Jaime Forero Valdés y el químico colombiano Joaquín Molano Campuzano, según el recuento de Pulgar Vidal, este acto fundacional pretendía continuar la obra cultural y científica de la Expedición Botánica, presidida por el sabio José Celestino Mutis con la posterior continuidad de Francisco José de Caldas, Jorge Tadeo Lozano, Eloy Valenzuela, Camilo Torres, Francisco Javier Matíz y Sinforoso Mutis entre otros. (Gutiérrez et al, 2012).

Bajo ese espíritu, y desde el entonces llamado Instituto Superior de Diseño y Proyectos para la Industria, se funda la Maestría en Diseño Industrial dirigida por el arquitecto Giulio Vinaccia y enfocada a ingenieros, arquitectos y

Figura 2. Portada del folleto de la Maestría en Diseño Industrial del Instituto Superior de Diseño y Proyectos para la Industria (año 1973). Archivo del programa de diseño industrial UJTL. Gráfico no publicado.

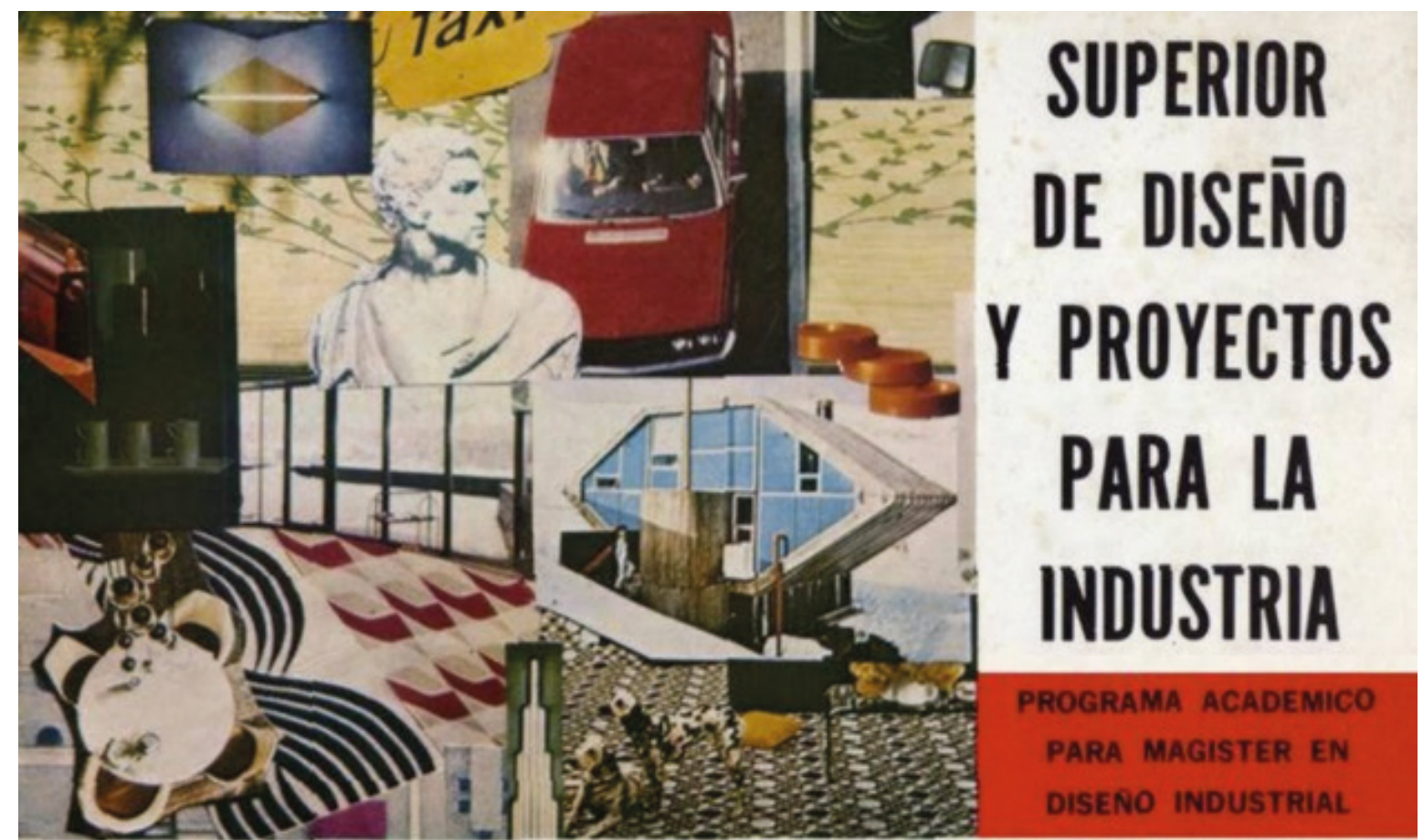

FUNDACION UNIVERSIDAD DE BOGOTA-JORGE TADEO LOZANO 
empresarios (Angulo, 2014), con una duración de cuatro semestres académicos, caracterizada por una jornada nocturna y con una intensidad de 24 horas por semana. Este programa de posgrado fue revisado posteriormente en 1976 por una comisión compuesta por Giulio Vinaccia, Jaime Gutiérrez Lega, Guillermo Sicard y Fernando Pineda. No hemos podido encontrar documentación sobre esos primeros egresados de la Maestría, pero al interior de los pasillos de la Universidad se dice que solo fueron dos los egresados de este posgrado, con intención de ser formados como docentes.

Mientras tanto en el año 1974, cuando la Rectoría se encontraba a cargo del doctor Jaime Uribe Urdinola, en la Universidad Jorge Tadeo Lozano se funda el programa de pregrado de Diseño Industrial, proceso dirigido por el arquitecto Giulio Vinaccia y donde participaron el investigador José de Recasens y el ingeniero Alberto Cruz (Gutiérrez et al, 2012). Meses después con un plan de estudios que evidenciaba una fuerte herencia de la escuela de Escuela Superior de Proyectación o Escuela de Ulm, inclusive en la traducción literal de alguna de sus asignaturas, seguramente por la influencia de los profesores alemanes Gerd Scussler e Ingo Werk (Fernández, 2009), se matricula la primera cohorte de estudiantes de diseño industrial y después de cursar el programa de diez semestres, comenzaron a graduarse a partir del año de 1980, entre los docentes ilustres que conformaron el primer grupo de profesionales en diseño industrial formados en una escuela colombiana se encuentra los profesores Jaime Pardo Gibson, Gerardo Silva García y Víctor Ramírez Pedraza. En una etapa posterior asume la decanatura Billy Escobar Reyes acompañado en sus funciones académicas por el arquitecto Germán Ramírez Pedraza y en la secretaría por María Margarita Venegas. Como hecho relevante, también en la década de los años 80 la Facultad es premiada con una distinción especial por la Corporación de Ferias y Exposición por su participación en la XIII Feria Internacional de Bogotá.

De acuerdo con los datos que suministra el documento Informe presentado por la facultad de diseño industrial con destino al Instituto Colombiano para el Fomento de la Educación Superior, los objetivos generales de este nuevo programa de pregrado consistían en complementar el desarrollo industrial colombiano por medio de la disciplina del diseño industrial y preparar el profesional del diseño industrial para Colombia. Respecto a los objetivos específicos: formar diseñadores según requerimientos de nuestra industrial, es decir, (a) Dirigidos primordialmente hacia la pequeña y mediana industria, (b) Con gran experiencia en el manejo de materiales y técnicas propias, como madera, metales (fundiciones nacionales), cerámica, cueros y algunos plásticos, (c) capaz de solucionar, en determinadas circunstancias, todo un problema, o sea, aspectos funcionales, estéticos, técnicos, económicos y de producción, (d) sólidos conocimientos del mercado nacional, sus preferencias, gustos, costumbres, niveles culturales y económicos. Y sus egresados adquirirán habilidades en diseño, tecnología, expresión, humanidades y sociales.

Para cerrar este apartado, y haciendo una reflexión sobre la construcción de conocimiento en el mundo, vale la pena destacar que el profesor Alfredo Gutiérrez escribió que un año antes, es decir, 1979, apareció la revista indexada Design Studies, primera en indagar sobre el potencial comparativo del diseño en todas sus especificidades de aplicación: diseño de ingeniería, de producto, arquitectónico y de planificación, informáticos y de sistemas (Gutiérrez, 2012).

\section{Información general contenida en el documento recuperado}

El procedimiento realizado para lograr la captura digital de las fotografías en blanco y negro del documento definido como archivo inactivo, fue utilizando un escáner Epson Stylus CX5600 con una resolución de 250 ppp.

En el capítulo 6 del documento, que se encuentra bajo el título de Recursos disponibles, se hace referencia a la planta física con la que disponía el programa de diseño industrial en 1981, allí se nombran unos laboratorios, talleres de máquinas que compartían con Bellas Artes y unos salones destinados para audiovisuales.

Figura 3. Salón y oficina del programa de diseño industrial (1981). Archivo del programa de diseño industrial UJTL. Gráfico no publicado.

Figura 4. Salones con estudiantes del programa de diseño industrial (1981). Archivo del programa de diseño industrial UJTL. Gráfico no publicado.

Figura 5. Salones con estudiantes del programa de diseño industrial (1981). Archivo del programa de diseño industrial UJTL. Gráfico no publicado. 
3
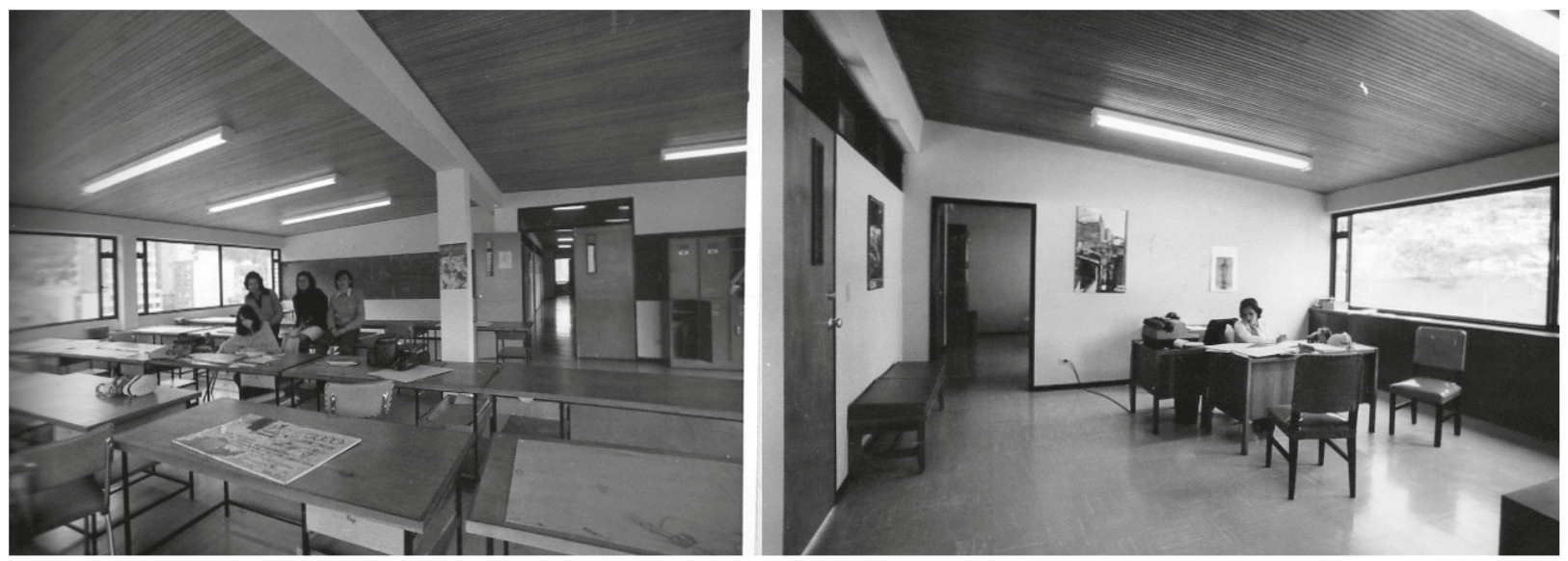

(4)
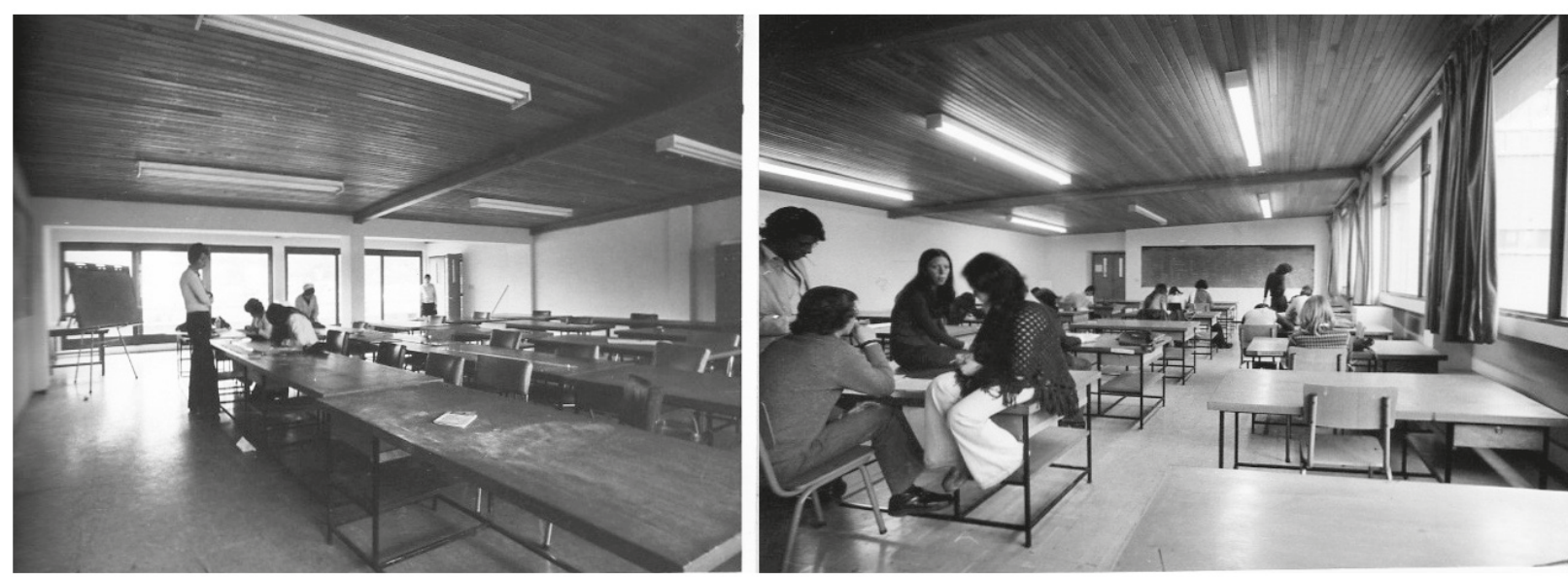

5
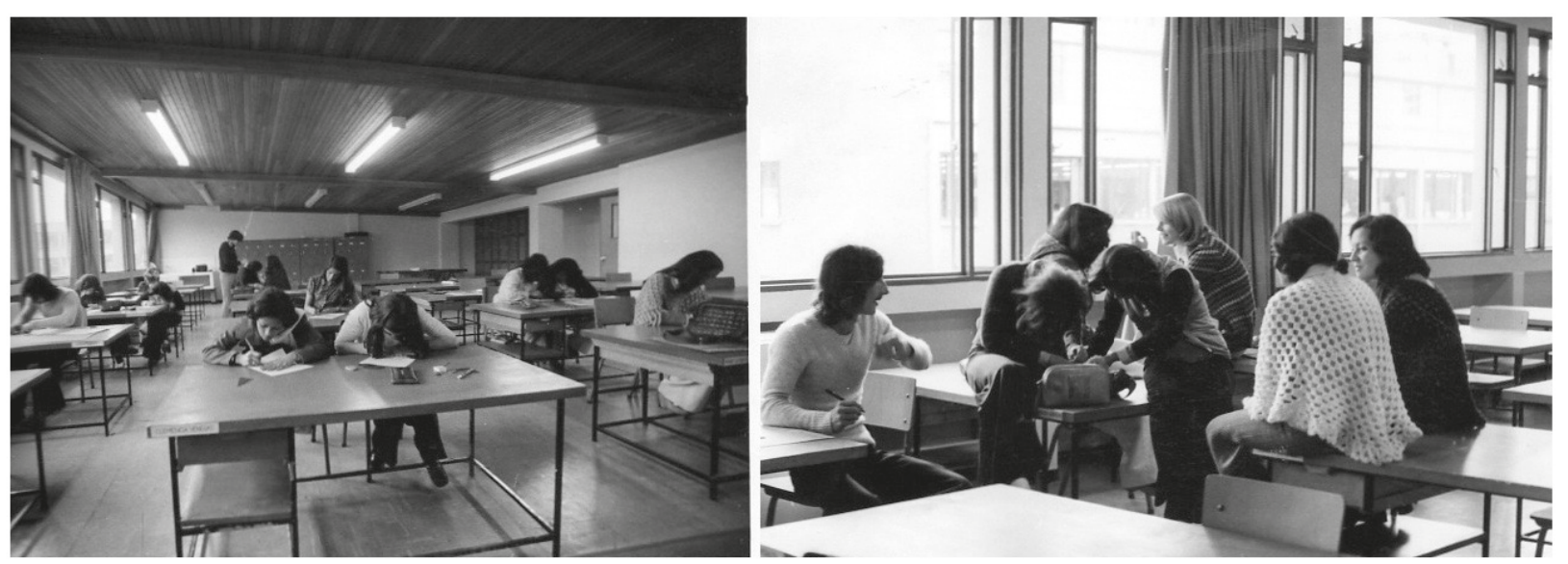
Los docentes del programa relacionados en dicho documento para los primeros años fueron: Rafael Acuña Quiroz, Juan Bautista Albánchez, Celia Fajardo de Anzellini, Iván Darío Arcila, Luis Enrique Berrocal, Juan Buenaventura, Gladys Camelo, Ismael Concha, Hernán Cortés Barrios, Ricardo Correa, Raúl Díaz Rodríguez, Constanza Gutiérrez Ramírez, Ana María Fernández, Mildred Fernández, Cecilia Cuéllar de Macmichen, Edgar Martínez Castro, Pablo Mendoza Duque, Diego Obregón, Mauricio Olarte, Fabio Ospina naranjo, Eduardo Peláez Herrán, Edgar pineda Cruz, Fernando Pineda Cruz, Amalia Posso de Akerman, Arturo Ramírez Yepes, Germán Ramírez Pedraza, Víctor Ramírez Pedraza, Arcelio Reyes Rodríguez, Luis Reyes Vejarano, Eduardo Rodríguez Ruiz, Rubén Rueda Erazo, Óscar Sierra Pérez, Juan Tejeiro Perdomo, Fernando Vanegas Ramón, Alfredo Vásquez Villarreal y Valerio Vinaccia Alpi.

\section{Proyectos de los estudiantes contenidos en el documento recuperado}

En el capítulo 9 del documento se encontró un registro fotográfico, a manera de imágenes individuales, sobre nueve proyectos destacados de los estudiantes del programa, aunque para infortunio de la presente investigación no fueron registrados los nombres de los autores. A continuación se presenta una relación de dichos proyectos.

Figura 6. Secadora de café (1981). Documento "Informe presentado por la Facultad de Diseño Industrial con destino al Instituto Colombiano para el Fomento de la Educación Superior", página 148. Archivo del programa de diseño industrial UJTL. Gráfico no publicado.

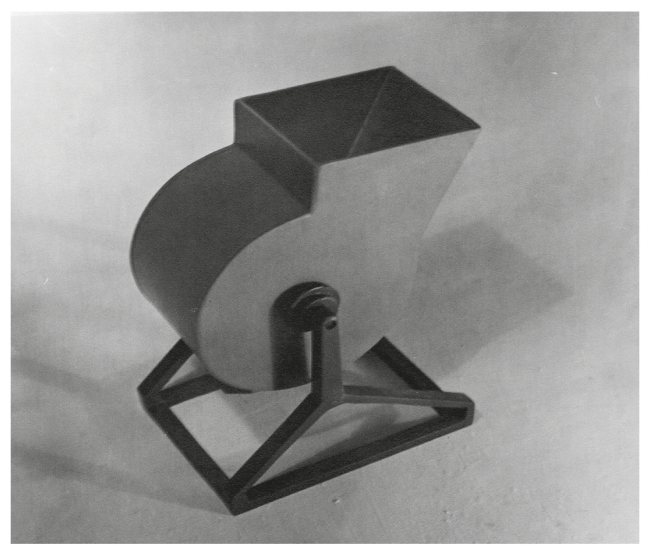

\section{Proyecto 1. Secadora de Café}

Destinada al pequeño caficultor, permite secar pequeñas cantidades de café (una carga) por medio de un cilindro interno provisto de divisiones, que al rotar alrededor del eje exponen el café a una corriente de aire caliente originada por un ventilador a través de resistencias eléctricas. Sus ventajas principales son economía y maniobrabilidad. (Párrafo transcrito del documento recuperado).

Figura 7. Filtro (1981). Documento "Informe presentado por la facultad de diseño industrial con destino al Instituto Colombiano para el Fomento de la Educación Superior", página 149. Archivo del programa de diseño industrial UJTL. Gráfico no publicado.

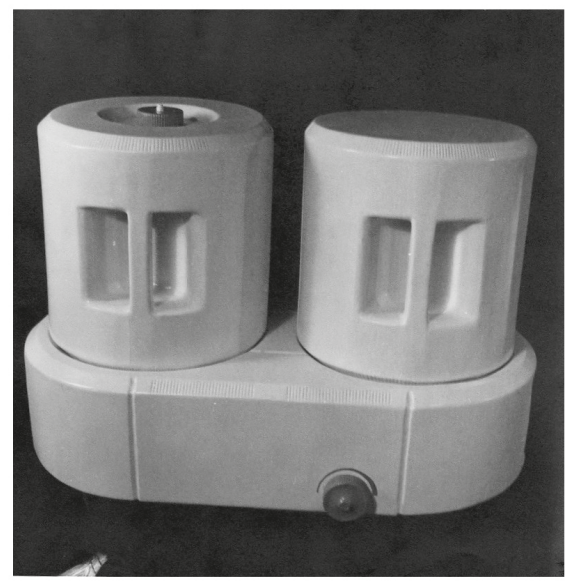

Proyecto 2. Filtro

Elimina bacterias y micro organismos del agua, por medio de una o varias bujías de cerámica, plata, carbón activado, y con una capacidad de 15 litros en el tanque de trasporte. El de almacenamiento da un rendimiento de 1.6 litros/minuto trabajando a presión de acueducto y 15 litros/día, baja gravedad (Párrafo transcrito del documento recuperado).

Proyecto 3. Licuadora portátil

De accionamiento manual, que por medio de piñones plásticos, alcanza 3.500 R.P.M. Sistema de cuchillas dobles en acero inoxidable y chupa en caucho para 
adherir a la superficie. Costo aproximado $\$ 750$ pesos colombianos. (Párrafo transcrito del documento recuperado).

Figura 8. Licuadora portátil (1981). Documento "Informe presentado por la facultad de diseño industrial con destino al Instituto Colombiano para el Fomento de la Educación Superior", página 149. Archivo del programa de diseño industrial UJTL. Gráfico no publicado.

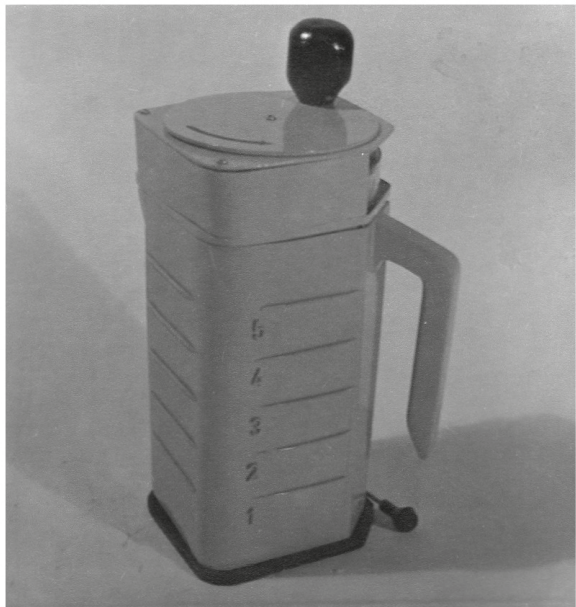

Proyecto 4. Automóvil de pedal

Sistema de trasporte personal, para utilizar en trayectos cortos y planos, como clubes, playas, complejos turísticos, instalaciones industriales y zonas urbanas especiales. Logra velocidades de 35 $\mathrm{Km} / \mathrm{h}$, por medio de un sistema de pedales dobles, tipo cigüeñal, trasmisión de varias velocidades. Posee además una estructura tubular, que protege en posibles volcamientos y sobre la que se puede fijar una carpa. La carrocería de plantea en fibra de vidrio. (Párrafo transcrito del documento recuperado).

Figura 9. Automóvil de pedal (1981). Documento "Informe presentado por la facultad de diseño industrial con destino al Instituto Colombiano para el Fomento de la Educación Superior", página 150. Archivo del programa de diseño industrial UJTL. Gráfico no publicado.

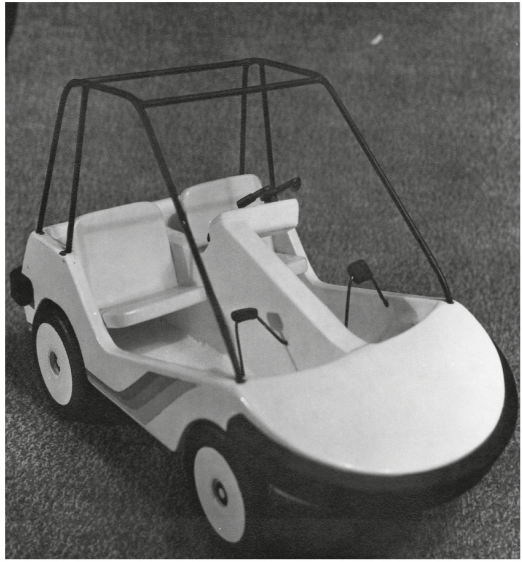

Proyecto 5. Bus

Diseño de carrocería para trasporte urbano, utilizando un chasis Dodge P-900, con capacidad para 11 personas sentadas (ancianos, mujeres embarazadas o con niños de brazos, impedidos) y 54 parados. Posee un sistema de registradora que se detiene automáticamente cuando el cupo se completa. En cada una de las entradas, se señala instantáneamente el número de cupos libres. (Párrafo transcrito del documento recuperado).

Figura 10. Bus (1981). Documento "Informe presentado por la Facultad de Diseño Industrial con destino al Instituto Colombiano para el Fomento de la Educación Superior", página 150. Archivo del Programa de Diseño Industrial UJTL. Gráfico no publicado.

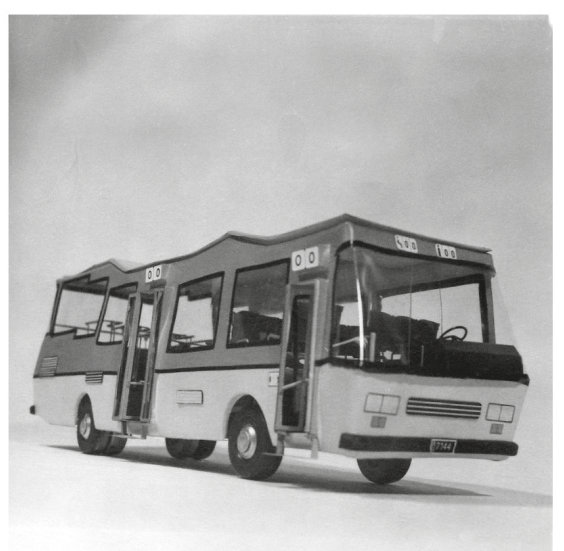


Proyecto 6. Andamio para construcción

Suministra las condiciones de seguridad necesarias para estas actividades, que no se tienen en cuenta en las soluciones existentes, como son: (a) Superficie segura y cómoda, dividida en secciones que permiten la llegada fácil de materiales a través de una canasta con ayuda de poleas. (b) Barandas de seguridad desmontables. (c) Caja de herramientas. (d) Escalera con pasamanos. (Párrafo transcrito del documento recuperado).

Figura 11. Andamio para construcción (1981). Documento "Informe presentado por la facultad de diseño industrial con destino al Instituto Colombiano para el Fomento de la Educación Superior”, página 151. Archivo del programa de diseño industrial UJTL. Gráfico no publicado.

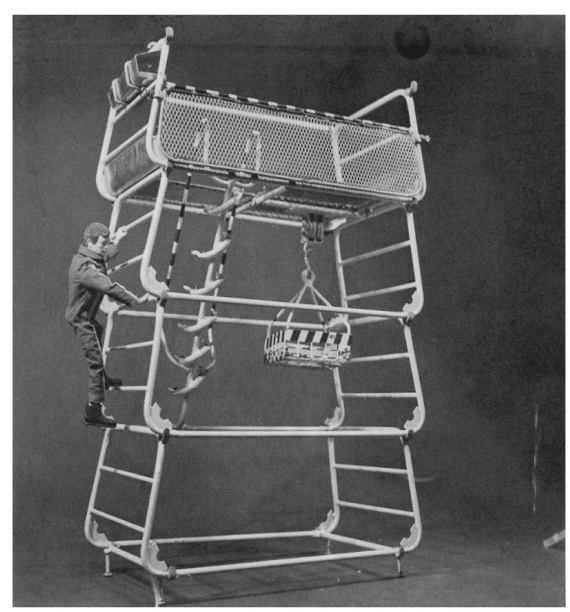

Proyecto 7. Ayudante de limpieza para cocina

Equipado con un motor eléctrico de $120 \mathrm{w}-12 \mathrm{ov}$, y 50-60 PS que mediante un eje flexible de movimiento a una cabeza portadora de elementos intercambiables como esponjas, brillos, paños y que provee también agua. Permite la limpieza de vajillas, ollas y en general de elementos de uso de la cocina. (Párrafo transcrito del documento recuperado).

Figura 12. Ayudante de limpieza para cocina (1981). Documento "Informe presentado por la facultad de diseño industrial con destino al Instituto Colombiano para el Fomento de la Educación Superior”, página 151. Archivo del programa de diseño industrial UJTL. Gráfico no publicado.

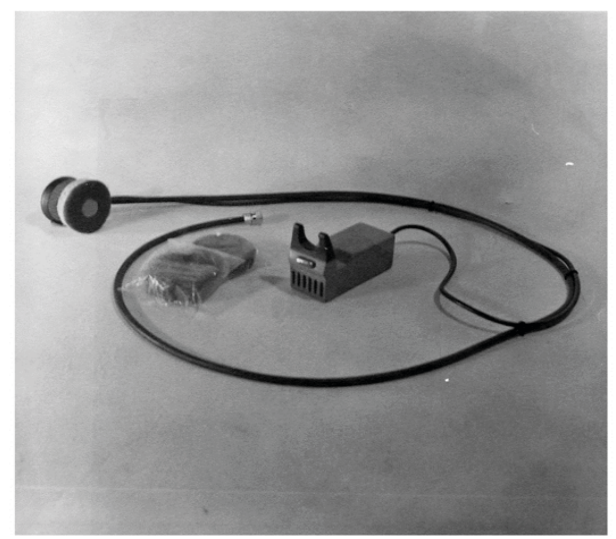

Proyecto 8. Carro para recolección manual de basuras

Consta de caneca desmontable para su vaciado, con pala integrada cuya función es recoger y depositar la basura en el recipiente, que a la vez sirve de tapa. La pala se acciona por medio de un pedal. La estructura, de tubo conduit y la caneca y porta elementos de fibra de vidrio, reducen el peso en un $50 \%$ con relación al recolector acrial. (Párrafo transcrito del documento recuperado).

Figura 13. Carro para recolección manual de basura (1981). Documento "Informe presentado por la facultad de diseño industrial con destino al Instituto Colombiano para el Fomento de la Educación Superior”, página 152. Archivo del programa de diseño industrial UJTL. Gráfico no publicado.

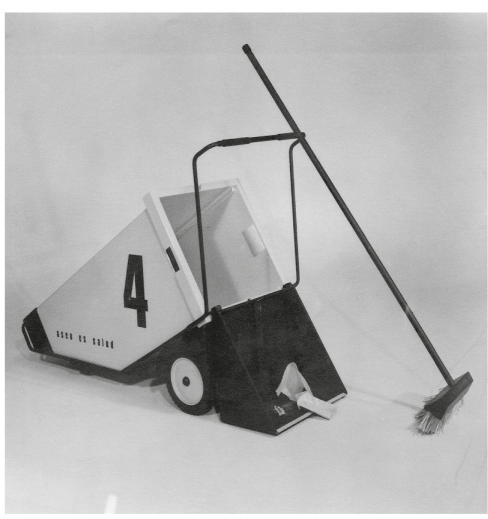


Proyecto 9. Despulpadora de café

Basada en el sistema actualmente utilizado de un cilindro que aprisiona la cereza contra un pechero, se le han adicionado mejoras sustanciales como la unificación del control de graduación del cilindro, aumento en la capacidad de la tolva y su movilidad para mantenimiento de la máquina; la unificación formal que protege los mecanismos internos y por último el cambio a un material de gran resistencia a la oxidación como es la fibra de vidrio. Al volante se le puede adicionar una correa que trasmite el movimiento de un motor eléctrico. (Párrafo transcrito del documento recuperado).

Figura 14. Despulpadora de café (1981). Documento "Informe presentado por la facultad de diseño industrial con destino al Instituto Colombiano para el Fomento de la Educación Superior", página 152. Archivo del programa de diseño industrial UJTL. Gráfico no publicado.

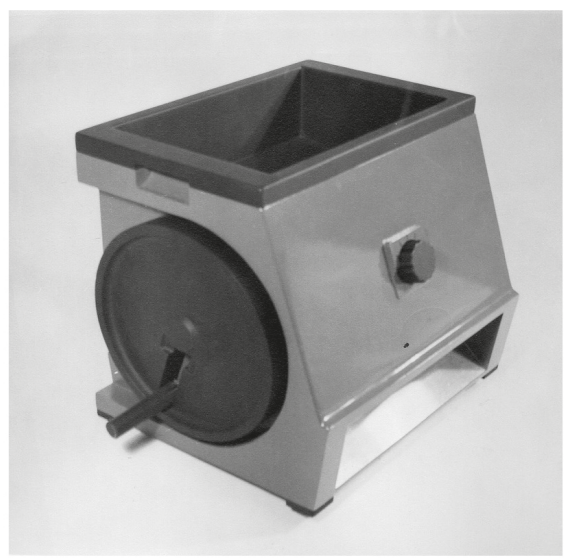

En una relación sobre los nueve proyectos presentados, se puede manifestar que siete $(2,3,4,5,6,7,8)$ de ellos fueron diseñados para contexto urbano y dos $(1,9)$ para un contexto rural. Del primer grupo, cuatro $(2,3,4,7)$ se destinarían para zonas privadas, concretamente el hogar y los restantes tres $(5,6,8)$ para zonas públicas; en su mayoría están pensados para una implementación en pequeña y mediana industria, desarrollando un nivel básico de tecnología y a un bajo costo. Respecto a los dos proyectos $(1,9)$ del contexto rural, que presentan un carácter agrícola, es sugerente descubrir que están pensados para ser aplicados específicamente en la cultura cafetera del país.

\section{Contexto histórico-político}

El marco natural que permite indagar sobre el pensamiento político, para construir una relación con el nacimiento de las escuelas de diseño industrial en Colombia, son las políticas públicas sobre la industria, la agroindustria y el comercio que se encuentran descritas en los Planes Nacionales de Desarrollo, las cuales se ajustan para cada periodo presidencial, sirviendo como hoja de ruta de los proyectos de gobierno.

Para el caso concreto del periodo que concierne a este documento, la concepción y primer impulso del programa de diseño industrial de La Tadeo, tuvo lugar, primero bajo el gobierno del presidente liberal Alfonso López Michelsen (1974-1978) bajo su "mandato claro" donde propuso cerrar la brecha entre la población campesina y urbana, y posterior se dio el del también presidente liberal Julio César Turbay (1978-1982) quien propendió por la producción, la seguridad y el empleo. Este par de periodos presidenciales heredaron un país soportado por el empuje de sus empresarios, quienes consolidaban la capacidad por trasformar las materias primas con maquinaria y herramientas, especialmente en el desarrollo del sector agrícola, acciones con las que se pretendía reavivar el comercio interno.

Bajo este panorama, la formación de profesionales de diseño industrial, como gestores de proyectos para la pequeña y mediana empresa, apoyó las iniciativas de desarrollo de estos dos gobiernos nacionales, incrementando el consumo interno y fortaleciendo la industria de bienes de capital. Unos años más tarde, el Plan Nacional de Desarrollo que comprende el periodo 1982-1986 todavía considera al comercio doméstico como la estrategia de reactivación económica nacional (Guerrero, 2014). Pero en la década siguiente, también nos recuerda la profesora Lorena Guerrero, que según la visión económica de Aníbal Quijano, varios países latinoamericanos fueron impactados por una fuerte crisis económica, siendo la academia un actor importante de apoyo, donde se contempló el sector exportador como una nueva estrategia de sustitución.

\section{Algunas conclusiones preliminares}

Primero, fue un logro para la presente reconstrucción histórica haber recuperado en una bodega este documento inactivo con cuarenta años de antigüedad, el cual incluía múltiples evidencias valiosas sobre los proyectos 
propuestos por algunos de los primeros estudiantes de diseño industrial en Colombia.

Segundo, este tipo de ejercicios que se aproximan a la arqueología de los medios (Burbano, 2013), por lo general dejan más preguntas que respuestas, y en el caso concreto de este documento, por las limitaciones encontradas en el texto y el registro fotográfico, todavía quedan espacios en blanco que podrán ser llenados cuando se logre un contacto directo con los protagonistas.

Tercero, en términos generales, la formación de los primeros profesionales de diseño industrial con un conocimiento de la pequeña y mediana industrial, así como el manejo de materiales y técnicas autóctonas, por un lado, dialogaba coherentemente con los requerimientos de la industria nacional y por otro, eran un soporte de los planes de desarrollo nacionales propuestos por los gobiernos de turno.

Cuarto, durante el periodo perteneciente al inicio del diseño industrial en Colombia, se propendió desde La Tadeo por trabajar los aspectos funcionales, estéticos, económicos y de producción, pero tal vez el aporte principal pudo ser contribuir con el desarrollo del comercio interno del país.

Por último, no existe suficiente información sobre el desarrollo técnico y tecnológico de estos proyectos de diseño industrial como para ser un tema que se pueda integrar a la presente discusión.

\section{Referencias bibliográficas}

Angulo, C. (2014): The Roots of Industrial Design Colleges in Colombia. Argentina: Foroalfa.

Buitrago, J. (2011): Creatividad Social, la profesionalización del diseño industrial en Colombia. Cali : Universidad del Valle.

Burbano, A. (2013): Inventions at the Borders of History. Italia: Neural, Bari.

Fernández, S.; Bonsiepe, G. (2009): Historia del diseño en América Latina y el Caribe. Industrialización y comunicación visual para la autonomía. Blücher.

Guerrero, L. (2014): El diseño industrial tadeísta frente a las políticas públicas de la industria:1970-2013. Sin publicar.
Gutiérrez, A.; Angulo, C. (2012): Cuatro décadas del Diseño Industrial tadeísta. Programa de Diseño Industrial. UJTL.

Gutiérrez, A. et al. (2014): El diseño industrial tadeísta en perspectiva: protagonistas, pensamientos, materializaciones 1974-2014, sin publicar.

PDI [Programa de diseño industrial]. (1981). Portada e índice del documento "Informe presentado por la facultad de diseño industrial con destino al Instituto Colombiano para el Fomento de la Educación Superior". [Figura No.1]. Recuperado en 2014.

PDI [Programa de diseño industrial]. (1973). Portada del folleto de la Maestría en Diseño Industrial del Instituto Superior de Diseño y Proyectos para la Industria. [Figura No.2]. Recuperado en 2010 .

PDI [Programa de diseño industrial]. (1981). Salón y oficina del programa de diseño industrial. [Figura No.3]. Recuperado en 2014.

PDI [Programa de diseño industrial]. (1981). Salones con estudiantes del programa de diseño industrial. [Figura No.4]. Recuperado en 2014.

PDI [Programa de diseño industrial]. (1981). Salones con estudiantes del programa de diseño industrial. [Figura No.5]. Recuperado en 2014.

PDI [Programa de diseño industrial]. (1981). Secadora de café. Documento "Informe presentado por la facultad de diseño industrial con destino al Instituto Colombiano para el Fomento de la Educación Superior", página 148. [Figura No.6]. Recuperado en 2014.

PDI [Programa de diseño industrial]. (1981). Filtro. Documento "Informe presentado por la facultad de diseño industrial con destino al Instituto Colombiano para el Fomento de la Educación Superior", página 149. [Figura No.7]. Recuperado en 2014.

PDI [Programa de diseño industrial]. (1981). Licuadora portátil. Documento "Informe presentado por la facultad de diseño industrial con destino al Instituto Colombiano para el Fomento de 
la Educación Superior", página 149. [Figura No.8]. Recuperado en 2014.

PDI [Programa de diseño industrial]. (1981). Automóvil de pedal. Documento "Informe presentado por la facultad de diseño industrial con destino al Instituto Colombiano para el Fomento de la Educación Superior", página 150. [Figura No.9]. Recuperado en 2014.

PDI [Programa de diseño industrial]. (1981). Bus. Documento "Informe presentado por la facultad de diseño industrial con destino al Instituto Colombiano para el Fomento de la Educación Superior", página 150. [Figura No.10]. Recuperado en 2014.

PDI [Programa de diseño industrial]. (1981). Andamio para construcción. Documento "Informe presentado por la facultad de diseño industrial con destino al Instituto Colombiano para el Fomento de la Educación Superior", página 151. [Figura No.11]. Recuperado en 2014.

PDI [Programa de diseño industrial]. (1981). Ayudante de limpieza para cocina. Documento "Informe presentado por la facultad de diseño industrial con destino al Instituto Colombiano para el Fomento de la Educación Superior", página 151. [Figura No.12]. Recuperado en 2014.

PDI [Programa de diseño industrial]. (1981). Carro para recolección manual de basura. Documento "Informe presentado por la facultad de diseño industrial con destino al Instituto Colombiano para el Fomento de la Educación Superior", página 152. [Figura No.13]. Recuperado en 2014.

PDI [Programa de diseño industrial]. (1981). Despulpadora de café. Documento "Informe presentado por la facultad de diseño industrial con destino al Instituto Colombiano para el Fomento de la Educación Superior", página 152. [Figura No.14]. Recuperado en 2014.

Quijano, A. (2004). El laberinto de América latina: ¿hay otras salidas? Revista venezolana de Economía y Ciencias Sociales, p.75-97.
UJTL [Universidad de Bogotá Jorge Tadeo Lozano] (1981). Informe presentado por la Facultad de Diseño Industrial con destino al Instituto Colombiano para el Fomento de la Educación Superior. Facultad de Diseño Industrial. 